Peter Anders 
Ferdinand Kösters

\section{Peter Anders}

Biographie eines Tenors

Mit 89 Abbildungen

Verlag J. B. Metzler

Stuttgart - Weimar 
Der ganz besondere Dank des Verfassers gilt Frau Sylvia Anders, die mit ihrem Engagement und ihrer Unterstützung die Herausgabe dieser Biographie ermöglicht hat.

Zu danken ist insbesondere auch der Stiftung zur Förderung der Hamburgischen Staatsoper für ihre großzügige finanzielle Unterstützung.

Besonders zu würdigen sind an dieser Stelle die großen Verdienste von Herrn Klaus Laubrunn, Quickborn, um die Veröffentlichung zahlloser Aufnahmen aus den Schallplatten- und Rundfunkarchiven, womit er wesentlich dazu beigetragen hat, daß die Erinnerung an Peter Anders lebendig geblieben ist.

Die Deutsche Bibliothek - CIP-Einheitsaufnahme

Kösters, Ferdinand: Peter Anders : Biographie eines Tenors / Ferdinand Kösters. Stuttgart ; Weimar : Metzler, 1995

ISBN 978-3-476-01294-4

ISBN 978-3-476-01294-4

ISBN 978-3-476-03588-2 (eBook)

DOI $10.1007 / 978-3-476-03588-2$

Dieses Werk einschließlich aller seiner Teile ist urheberrechtlich geschützt. Jede Verwertung außerhalb der engen Grenzen des Urheberrechtsgesetzes ist ohne Zustimmung des Verlages unzulässig und strafbar. Das gilt insbesondere für Vervielfältigungen, Übersetzungen, Mikroverfilmungen und die Einspeicherung und Verarbeitung in elektronischen Systemen.

(C) 1995 Springer-Verlag GmbH Deutschland

Ursprünglich erschienen bei J.B. Metzlersche Verlagsbuchhandlung und Carl Ernst Poeschel Verlag GmbH in Stuttgart 1995

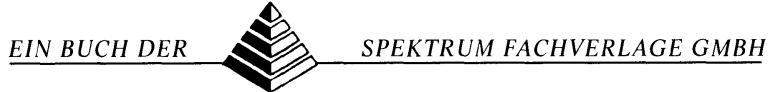




\title{
INHALT
}

Vorwort VII

EINLEITUNG 1

Der klingende Atem Gottes - Die letzte Premiere 1

\author{
DAS LEBEN 5 \\ Kinder- und Jugendjahre 5 \\ Studienzeit und erste Auftritte 11 \\ Stationen 19 \\ Das erste Engagement in Heidelberg 19 Darmstadt 30 Köln 41 \\ Hannover 51 München 63 Berlin 102 \\ »... und neues Leben blüht aus den Ruinen" 129 \\ Hamburg 147
}

DAS KÜNSTLERISCHE SCHAFFEN 203

Der Opernsänger 206

Der Konzertsänger 214

Peter Anders und die Operette 219

Schallplatten und Rundfunk 221

DER UNFALL 225

Nachwort 233

Personenregister 247 


\section{VORWORT}

»Dem Mimen flicht die Nachwelt keine Kränze! - Des Sängers Ruhm jedoch ist dauerhafter.«

Das schrieb die Deutsche Grammophon-Gesellschaft Ende 1954 in einem Sonder-Werbeprospekt über ihren Star-Sänger Peter Anders, der wenige Wochen zuvor, am 10. September, den schweren Verletzungen erlegen war, die er sich bei einem Autounfall zugezogen hatte.

Die Gesellschaft begründete ihre Aussage mit der Technik, die es ermögliche, die Kunst eines Sängers mittels Tonband und Schallplatte auch dann noch fortleben zu lassen, wenn sein Mund schon längst verstummt ist. Der Schreiber dieser Zeilen konnte damals nicht ahnen, daß seine Prophezeihung im Falle Peter Anders spektakulär in Erfüllung gehen und auch noch vier Jahrzehnte nach seinem Tod Gültigkeit haben würde.

Alle Schwüre der Treue, des Nievergessens, die damals an der Bahre des Sängers abgelegt wurden, gelten ungebrochen fort. Wie nur ganz wenige Große des Musiktheaters, die durch herausragende künstlerische Leistungen Maßstäbe gesetzt und durch ihr menschliches Wesen und ihre Gesamtpersönlichkeit ein Millionenpublikum - sicherlich mit Hilfe der Technik - gewonnen und beglückt haben, gehört Peter Anders zu den »Unvergeßlichen«. Von den deutschsprachigen Sängerpersönlichkeiten sind neben ihm beispielhaft zu nennen: Maria Cebotari, Heinrich Schlusnus, Joseph Schmidt und Richard Tauber.

Durch Rundfunk und Schallplatte war Peter Anders einem Millionenpublikum ein Begriff. Er war eine Berühmtheit; wenn man Anfang der fünfziger Jahre in Deutschland von »Tenor« sprach, meinte man Peter Anders. Seine Popularität war für einen »ernsten« Sänger, einen Opern- und Konzertsänger, unvorstellbar groß: selbst in den Kreuzworträtseln lautete die Antwort auf die Frage nach einem berühmten deutschen Sänger: »Anders«.

Gewiß, diese Popularität beruhte nicht allein auf seiner Tätigkeit als Opernoder Konzertsänger, sondern ganz überwiegend auf den von ihm gesungenen Operettentiteln, die täglich über alle deutschen Rundfunksender gingen. Wer heute eine Programmzeitschrift von beispielsweise 1953 aufschlägt, findet den Namen Peter Anders mehrmals täglich in den Programmankündigungen. Als Interpret des Schlagers »Granada« hörte man seine Stimme aus den Musikboxen unzähliger deutscher Gaststätten und Wirtschaften erklingen

Da mußte zwangsläufig sein Autounfall am 5. September 1954 und sein Tod fünf Tage später die Menschen in Deutschland bewegen. Diese Ereignisse und die Meldungen aus dem Krankenhaus waren damals Tagesgespräch. 
In den ersten Jahren nach seinem Tod hielt die Treue seiner Verehrer, ja sie steigerte sich sogar noch. 1961 berichtete »Bild am Sonntag « von Umfragen, bei denen Peter-Anders-Schallplatten der Verkaufs-Hit Nr. 1 waren, noch vor den damals sonst die Schlager- oder Hitparaden beherrschenden Schlagersängern in Deutschland.

Der Intendant der Hamburgischen Staatsoper, Dr. Günther Rennert, sprach in der Trauerfeier für den Künstler vom »Geheimnis des Außergewöhnlichen«. Peter Anders war in der Tat eine außergewöhnliche Persönlichkeit.

Wer ihn nicht kannte, horchte am Radio auf, wenn seine Stimme erklang. Es war, als ob die Sonne aufging. Auf seinen vielen Aufnahmen, die er hinterlassen hat, ist dieses Faszinierende an seiner Stimme, diese Strahlkraft, die den Zuhörer betörte und fesselte, auch heute noch zu spüren.

Ich selbst habe Peter Anders als Schüler etwa um 1952 herum erstmals bewußt im Rundfunk gehört. Seitdem hat mich diese Stimme, hat mich aber auch der Mensch Peter Anders nie mehr losgelassen, obwohl ich ihn nie auf der Bühne oder auf dem Konzertpodium erlebt habe. Noch heute bin ich betrübt, daß ich als Sechzehnjähriger nicht die Mittel hatte, mir eine Konzertkarte zu kaufen, als Peter Anders 1953 in Bad Godesberg, heute Stadtteil meiner Vaterstadt Bonn, auftrat. So bleibt als »lebendes Bild« von Peter Anders in mir nur eine Fernsehsendung erinnerlich, die Ende April 1954 ausgestrahlt wurde, und in der junge Nachwuchssänger vorgestellt wurden. Die Mutter eines Schulfreundes mußte ich damals bitten, mir am frühen Abend im Gästesaal der von ihr betriebenen Wirtschaft den Fernsehapparat eigens für mich und meinen Freund anzustellen, weil wir zu Hause ein solches Gerät nicht besaßen.

Später kam zu diesen Bildern noch ein Auszug aus dem Film »Befreite Musik« hinzu, der eine Szene mit Peter Anders beim ersten Nachkriegskonzert der Berliner Staatsoper 1945 zeigt: einen Ausschnitt mit der Arie »Wohin seid ihr entschwunden?«.

Als ich 1976 den »Peter-Anders-Freundeskreis« gründete und danach die Bekanntschaft mit Frau Professor Susanne Anders und ihrer Tochter Sylvia machte, erlebte ich eine weitere verblüffende Überraschung: Mehr als zwei Drittel der Mitglieder waren jüngere Menschen, die Peter Anders nie auf der Bühne erlebt hatten und ihn nur von Schallplatten kannten. Und das mehr als zwanzig Jahre nach seinem Tode!

Gibt es einen besseren Beweis für die Faszination, die von diesem Sänger ausging, für die Kostbarkeit seines künstlerischen Vermächtnisses, das er unauslöschlich hinterlassen hat?

Der bereits früher aufgekommene Gedanke, die Laufbahn des Sängers Peter Anders nachzuzeichnen, ließ sich durch den Tod von Frau Anders 1979 nicht verwirklichen. Er ist jetzt erneut aufgegriffen worden.

Das vorliegende Buch will dem Musikfreund die Persönlichkeit des Menschen Peter Anders näherbringen, die Stationen seiner Laufbahn aufzeichnen und seine künstlerischen Leistungen würdigen. Es soll das Geschehen jener Jahre schildern, das politische und künstlerische Umfeld, die Umwälzungen durch Krieg und 
Nachkriegszeit, und auch auf die Künstler eingehen, die mit Peter Anders gemeinsam aufgetreten sind.

Peter Anders hat mit seiner kostbaren Stimme Millionen Menschen beglückt, hat ihnen ungezählte Stunden der Freude und der Besinnlichkeit geschenkt. Doch trotz aller Erfolge blieb er immer fröhlich, sympathisch und vor allem bescheiden, ohne die sonst Tenören oft nachgesagten Allüren. Allen Beifall, alle manchmal enthusiastischen Sympathie-Bekundungen hat er stets bescheiden lächelnd abgewehrt. Es schien, als wolle er, wie Herbert Grenzebach es einmal geschildert hat, sagen: »Ach laßt doch, es macht mir ja selbst soviel Freude!«. 